Meta

Journal des traducteurs

Translators' Journal

\title{
Translation between Typologically Diverse Languages
}

Donald Philippi

Volume 34, numéro 4, décembre 1989

URI : https://id.erudit.org/iderudit/003834ar

DOI : https://doi.org/10.7202/003834ar

Aller au sommaire du numéro

Éditeur(s)

Les Presses de l'Université de Montréal

ISSN

0026-0452 (imprimé)

1492-1421 (numérique)

Découvrir la revue

Citer cet article

Philippi, D. (1989). Translation between Typologically Diverse Languages. Meta, 34(4), 680-685. https://doi.org/10.7202/003834ar d'utilisation que vous pouvez consulter en ligne.

https://apropos.erudit.org/fr/usagers/politique-dutilisation/ 


\section{TRANSLATION BETWEEN TYPOLOGICALLY DIVERSE LANGUAGES}

DONALD PHILIPPI

San Francisco, U.S.A.

My remarks refer only to languages belonging to completely different typological classifications, and particularly to Japanese and English. What I say does not apply to translation between Indo-European languages such as between German and English or between Spanish and Italian. These languages are structurally so similar, and cognates are so prevalent, that the difficulties in translation between them are of a different order from those which I will discuss here.

\section{WHAT IS TRANSLATION?}

Translation is a culturally acquired, high-precision and multi-faceted skill. Some of the skills are learned motor skills which have become an automatic as reflexes; others are highly sophisticated techniques of retaining, indexing or retrieving information; a knowledge of cultural and technical contexts is involved; and on the highest level, linguistic sensitivity of the highest order is needed. But more. Translating needs to be acquired and maintained like other complex skills, such as playing the violin or ballet dancing. Constant practice is required. After an absence of several weeks, a translator is out of condition and finds it difficult to get back into the schedule. At first, there is a sense of strangeness, and it takes ten days to two weeks before a normal level of speed can be regained. Very often we don't realize how much we rely on constant reiteration of familiar processes in order to build up our speed and efficiency.

When we try to analyze and define the translating process between typologically diverse languages, we immediately notice that there are no words to describe what goes on! How hard it is to translate into intelligible language what goes on within the translator! A metalanguage is definitely called for so that we can define what happens in words borrowed from other frames of reference or else make up our own words.

\section{STRICTLY IMMATERIAL}

Translation, at least between typologically diverse languages, is an abstract art; it is strictly independent of any subject matter. It is a methodology which can be applied to any subject matter.

Whatever happens after a translator sits down at the computer, it isn't anything material. What realm do we enter when we boot up our computer, attune our mental faculties to that odd wavelength of ours, and ascend into the ethereal realm of the translator's daily praxis? The translator's consciousness is not focused on any object, but is rather liberated from the world of material objects. The translator's realm is on a highly abstract plane, rather like that of a mathematician, grammarian or logician. The material objects are distanced. The domain of consciousness in which the translator operates is detached from the whole natural world. Abstracted from reality, the translator operates outside of the spatio-temporal system in the world of pure consciousness. As Edmund Husserl would say: "Between the meanings of consciousness and reality yawns a veritable abyss." (Husserl, Ideas, p. 138.) It is a state of abnormally heightened linguistic 
acuity, of heightened awareness of incorporeal distinctions, many of which are not actually present in the written text. It is also a state of heightened memory, which I will call panmnesia.

The translator's work is transcendental in that it does not deal with any material reality but only manipulates bits of memory (engrams) which inhabit a virtual space, apart from real space. The translator's world is a world of incorporeal experiences based on contact with non-material relationships and concepts. The habit of dealing with these incorporal substances gives translators a good ability to attain high degrees of abstraction and to intuitively perceive relationships which are not obvious on the surface. Ghostly relationships are moving around almost imperceptibly in the ether; it is our task to identify and catch them, pin them down, then radically demolish them and reassemble them into an equivalent in the target language.

\section{PANMNESIA IN THE LAND OF ENGRAMS}

The translating process involves the organization of memory traces (here called "engrams") which are reinforced by repeated impressions. Engrams (mnemes) can be both individual and collective. First, the translator sits down to the computer and boots it up, while simultaneously attaining a state of heightened abstraction or intuition. Then the process of radical demolition and reconstruction begins.

The state entered by a translator when he/she begins translating is similar to the state which a mystic enters when he/she goes into the dimension of prayer or contemplation. At the start of each session, the translator's mind changes gear and goes into an altered state of intense concentration. While the mystic's realm is contemplation, the translator's realm is active and productive, but it also requires intense concentration and an immense degree of abstraction (sense-awareness is withdrawn from the surrounding material objects).

I will call it panmnesia, in the sense that it is a state in which all available memory resources from all sources whatever are mobilized, whether they are present in the mind, in past recollections, in dictionaries and reference books, in notes and databases, and so on. The memory bits are both individual and collective and can be thought of as precipitates of the psychic functioning of two entire ancestral lines: the accumulated experiences of two linguistic groups, repeated millions of times, and encapsulated into engrams, or bits of memory.

\section{IT WAS INVENTED FOR US!}

Every translator or would-be translator knows that word-for-word translation is an impossibility. The Japanese utterance has a construction different from that of the English sentence. Day after day we stare again and again at (what looks like, but usually is not) a confused mess of Japanese written output saturated with every known variety of illogic and usually containing several recondite kanji combinations not to be found in any dictionary anywhere. How does one even begin to tackle such a tangled jumble? One thing is always certain: the Japanese word order will never be the same as the English word order. The pivotal portion of the Japanese utterance is the predicate; the verb comes at the end of the sentence; and one Japanese utterance can sometimes be broken down into two, three or more shorter English sentences. Radical deconstruction is needed.

The computer, the word processor was invented for us. Before the days of word processing we translators had to figure out in detail every mouthful (I scarcely dare call a Japanese utterance a sentence!) before even beginning to put anything down in writing in English. How often did we have to retype entire pages because bits taken from a Japanese mouthful needed to be shifted around to different location in the English sentences arising 
from our demolition of the Japanese mess. How much more convenient to do this on a screen before committing oneself to paper!

Today it no longer really matters where we start, since the word processor enables us to move snippets around on the page with perfect freedom. We can even start to translate the Japanese utterance in exactly the same order in which it meets the eye, beginning with the very first phrase, even though we are sure that the first phrase may finally be in the middle or at the end of the English equivalent. Then, after we have figured out something about the logical subordination of the parts of the Japanese utterance, we can deploy them experimentally in the most suitable English order, breaking up longer utterances into shorter English sentences as called for. The detached bits of the Japanese utterance float around freely in the ether on our computer screens, seeking other bits to which they can bond in an English-sounding sentence.

\section{SERIES OF EXPLOSIONS}

Japanese-to-English translation is like a series of explosions in each of which the translator literally demolishes a Japanese utterance, leaving the detached pieces (which are really memory-bits, or engrams) to float around in a sort of gigantic kaleidoscope. Substitute English frameworks (matrices) are then tried out, and the engrams are tentatively fitted into them. Numerous modifications of the structures may be necessary before convincing English sentences are evolved.

My assumption here is that Japanese-to-English translation is rather like a process of radical demolition, in which a confused-looking mass of raw materials is dynamited and then reassigned, after considerable shifting of positions on the screen, to neat, new sentences in English. In fact, maybe that's what goes on in the translator's mind while translating a Japanese job: a series of invisible explosions taking place on a high level of abstraction. In a burst of deconstructive passion, one first detaches one by one, in any order at all, the phrases which are the raw materials of the old structure, being careful to preserve them all and keep any of them from disappearing. They do not need to be retained in their original order - they can be stored in any order for the time being - but they must not be misplaced or thrown out by mistake, because they are ingredients which will go into the final translation product. (An exception is when one discovers that the Japanese utterance contains exactly the same phrase twice; redundant elements can safely be discarded.)

The original utterance is exploded, the resonating engrams are liberated, and finally a mutated utterance is reconstituted allowing the engrams to resonate properly.

\section{RESONATING ENGRAMS}

A text must be recognized as a complex artifact made up of explicit or implicit engrams, each one resonating with many levels of connotations.

When I say that the engrams, detached from their original matrix, are floating around, that does not mean to say that they are in a state of utter chaos. Each engram possesses cultural, personal, contextual and technical resonances. The contextual resonances are especially important in translation; each engram was extracted from a specific context. Subordinate engrams (micro-engrams) which were appended to other engrams (macro-engrams) in the original matrix will continue to resonate in subordination to their super-engrams even when physically detached from them. Engrams tend to group themselves in the best possible shape or figure, tending toward meaningfulness, completeness, and simplicity. When the new matrix is established with its own code system, the microengrams will be attracted towards certain slots in it which will enable them to resonate best with reference to their macro-engrams, which will now occupy a different position in 
the matrix. The resulting artifact, the translation, should be full of resonances reminiscent of the resonances of the original, although the codes and rules of both matrices are quite different.

An unsuccessful translation in one where the engrams cannot display their proper resonances in the new matrix, perhaps because the translator has disregarded the codes applicable in the matrix, possibly because he has failed to identify the resonances of the engrams or has even failed to notice some engrams (some of which are implicit in the original matrix).

\section{KINDS OF ENGRAMS}

The translation as a whole need not, in fact cannot, be present in the consciousness, but the explicit parts of it can be present on the screen. Just as the cursor moves from character to character, so the focus-point of consciousness moves about in the mind, moving engrams one after another from the background into the foreground. The light of consciousness temporarily highlights each engram, and eventually the whole reconstituted utterance is highlighted when it is ready.

The following kinds of engrams are always present in translation.

1) Endogenous engrams. These are engrams which originate in the text. They are the various types of graphemes, morphemes, or semantemes which are identifiably present explicitly or implicitly within the written text.

a) Explicit engrams are those which are graphically present, which correspond to words or phrases written out in the original text. They are preserved as floating bits when the original artifact is exploded.

b) Implicit engrams are virtual meanings which do not show up as actual words or phrases in the original but which must be gathered by the translator and possibly assigned explicit values in the new matrix. Examples of implicit engrams are engrams identifying the omitted subject of a Japanese utterance or the number (singular or plural) of every noun and verb in the Japanese utterance. The number is an important example; the translator will gather up information about whether every engram refers to something singular or plural. Very often the Japanese utterance has no subject; the translator will sometimes supply engrams for missing subjects. Especially important are the engrams having to do with the author's presence or absence. The author may assert himself or may try to be invisible, at least graphically. In certain types of translation, the translator must remain aware of the tone of voice - assertive, deprecative, doubting, exclamatory - or whether the speaker is male or female.

2) Exogenous engrams. These are engrams which are supplied from outside the text. They include any kind of supplementary information which may have any bearing on the meaning or translation of the text. They are bits of technical or cultural information which the translator discovers from elsewhere in the document (by consulting an abstract or the figures or tables) or from external sources such as dictionaries, glossaries, notes, reference books, databases, inquiries made by the translator, recollections of past jobs, academic courses taken by the translator, etc. Although exogenous information is always helpful and interesting, it may be of questionable reliability (Japanese dictionaries are notorious for their outright mistakes), often tends to be contradictory and must always be carefully evaluated. "Technical information," which is commonly claimed to be of immense importance in translation, is simply a collection of these dubious facts requiring careful information.

3) Mechanismic engrams. The translator has a toolbox of common mechanisms which he has learned by constant repetition. They too are present in the translating process 
as engrams which I will call "mechanismic." They must be in constant operation as a series of sub-systems working in the background throughout the process. I visualize them as permanently occupying a certain area of memory (the "translator's toolbox" section) where they are constantly on call. A translator who lacks this section is working under a severe handicap, and his output cannot be expected to be successful. A carpenter would not be able to function without his toolbox, and a translator would be lost without his bag of mechanisms. I can name four of these mechanisms. No doubt others can identify still others.

a) The scanning engram. The translator has a well-organized mechanism whereby he rapidly scans a Japanese utterance to find subjects, subordinate clauses, and the predicate. The results of this scan are useful in constructing the English matrix. Speed-reading is the key to successful translation. The ability to read Japanese text rapidly, immediately formulate a preliminary assessment of its structure, and supply a tentative English matrix is probably the central mechanism in the translator's operations. The translator must be able to focus on the overall picture: the structure of the Japanese utterance as a whole, keeping in mind at the same time how the English matrix will be constructed. Translators who cannot scan Japanese text rapidly, or who must stop to look up unfamiliar kanji, are not able to grasp the utterance as a whole at a glance. What an experienced translator can accomplish in a few seconds, they must laboriously do over a period of minutes. The result is an inferior translation made with excessive expenditure of time and energy, dissatisfied clients, and poor earnings.

b) The suspicion engram. The translator subjects every endogenous and exogenous engram to a process of suspicion. It is especially necessary to remain constantly vigilant against inconsistencies, misprints and typographical errors, omissions, and mistakes in the text. This engram often supplies the key to interpreting a written passage which does not "make sense". A punctuation mark has been omitted, or an unneeded grapheme has been added by mistake. Translators must distrust punctuation marks. Japanese writing reproduces the order of thoughts in Japanese speech or thinking, and punctuation is used in ways which often seem idiosyncratic. It would be a dreadful mistake to assume that there ought to be a correspondence between every Japanese half stop and an English comma and between every Japanese full stop and an English period.

c) The ambiguity engram. The translator has a mechanism whereby he immediately identifies ambiguities in the Japanese text which will create difficulties in the translation. For example, it is often quite difficult to determine whether an adjective modifies only the noun directly following it or a series of nouns (red raspberries and strawberries, fresh apples, oranges and bananas).

d) The self-censorship engram. The translator censors the engrams to purge them of unwanted material, usually dictated by style books, editors, or clients. The likes and dislikes of editors, authorities or clients are unpredictable and irrational. The translator merely acquiesces in these irrational taboos and tries to censor out certain words or expressions if an editor has an irrational dislike of them.

Not all engrams will find their way into the new matrix. Some engrams will be highlighted in the foreground; others will remain in the background and may not need to be called upon after all.

\section{BISOCIATION AND TRANSLATORS' WAYS OF THINKING}

After we have exploded the Japanese utterance and gathered together a collection of engrams, explicit or implicit, we now deploy the parts experimentally in a suitable English order, breaking up longer utterances into shorter English sentences as called for. This is done by means of the mechanisms mentioned above. 
The scanning mechanism is used to break down the Japanese utterance tentatively into its component parts and to build up the beginnings of an English matrix. One Japanese utterance may produce more than one English sentence. The Japanese utterance is a complex system in which the parts are organized according to a certain linguistic or perceptional pattern. In order to create a semantically equivalent English version, one needs to extract the components and reorganize them into one or more English sentences according to a different perceptional pattern. One proposes one or more tentative English sentence-structures which hopefully will work, each one a possible framework (matrix) into which the floating phrases can be inserted. One moves components in and out and around, molding, modifying, shortening, smoothing. The first try is seldom the final one. Shapes have to be moved about quite a lot. After considerable trial and error, one finally ends up with one or more English sentences which the translator claims are the heirs (mutations) inheriting and replicating the demolished Japanese utterance. If the fourth or fifth element in the Japanese utterance will come in first place in the English sentence, we will need to move its modifiers there too. The resulting equivalent must have good coherence.

It is also clear that the translator is practicing what Koestler calls "bisociation", i.e., manipulation of engrams between two mutually incompatible frames of references (matrices). Koestler defines humor in terms of bisociation, when a situation or idea is perceived in two self-consistent but habitually incompatible matrices (frames of reference) (Koestler, The Act of Creation, p. 35). Bisociation is the very essence of translation. Translators habitually manipulate engrams back and forth between such matrices, while the monolingual operate exclusively within one matrix and recognize only one set of rules for their linguistic praxis.

The result of all this is that translators have a way of thinking which is different from the straightforward, one-dimensional thinking practiced by the monolingual. The translator's approach to the world is skeptical, sometimes even cynical, since he is able to see through certain pretences and inanities which are masked by linguistic hazes. Monolingual thinking operates on a single plane, reducing everything to one common denominator; the translator resembles a cultural anthropologist, who mediates back and forth between two different cultural worlds, trying to interpret one to the other. Translators habitually think on a number of different levels all at once; the mechanisms by which they operate - those immaterial, highly abstract procedures for manipulating engrams - matter more to them than the actual content of what they are translating. They very rarely remember anything they have translated. Only occasionally do they pause to chuckle at the statements they are translating. 